\title{
Reverse (convex) conchal bowl: Report of eight cases and its correction by modified conchoplasty technique
}

\author{
Subhash Chandra Shetty MS ${ }^{1}$, Sanjeev Gupta MS ${ }^{1}$, Suhel Hasan MS ${ }^{1}$, Mahil Cherian $\mathrm{MCh}^{2}$, \\ Vijay Joseph $\mathrm{MCh}^{2}$, Norman Guido $\mathrm{MS}^{2}$ \\ Departments of ${ }^{1}$ Otolaryngology and Head and Neck Surgery, and ${ }^{2}$ Plastic and Reconstructive Surgery, \\ St John's Medical College Hospital, Bangalore, India
}

SC Shetty, S Gupta, S Hasan, M Cherian, V Joseph, N Guido. Reverse (convex) conchal bowl: Report of eight cases and its correction by modified conchoplasty technique. Can J Plast Surg 2000;8(6):233-238.

Many different congenital malformations of the external ear are encountered in otology and plastic surgery practice. However, there has been only one report in the literature of reverse (convex) conchal deformity in otherwise normal ears. Eight such cases were encountered in the combined otology and plastic surgery practice at the authors' institution. The condition was bilateral in two patients and unilateral in six patients; these patients had no other otological abnormalities. Two patients sought surgical correction. Modified conchoplasty, done by excising and replacing the conchal cartilage in reverse fashion, is presented. Controversies surrounding the embryogenesis of concha are also addressed.

Keywords: Conchoplasty; Convex concha

\section{Conque inversée (convexe) : Rapport sur huit cas et leur correction par une technique modifiée de conchoplastie}

RÉSUMÉ : De nombreuses malformations congénitales de l'oreille externe se rencontrent en otologie et en chirurgie plastique. Par contre, dans la littérature, on ne relève qu'un cas de conque inversée (convexe) associé à des oreilles par ailleurs normales. Huit de ces cas ont été relatés dans l'établissement où pratiquent les auteurs en otologie et en chirurgie plastique. Le problème s'est révélé bilatéral chez deux patients et unilatéral chez six autres; ces patients ne présentaient aucun autre problème otologique. Deux patients ont demandé une correction chirurgicale. On explique ici la technique de conchoplastie modifiée, effectuée par excision et inversion du cartilage et on aborde les controverses entourant l'hypothèse selon laquelle le problème serait d'origine embryogénétique.

$\mathrm{M}$ inor variations in the external ear are numerous. These include anotia, microtia, macrotia, cryptotia, prominent ears and question mark ear, in addition to the anomalies of the lobule, accessory auricle, preauricular sinus and fistula. However, Yii and Walker (1) reported one additional anomaly of the auricle. In a 12-year-old boy of Asian origin, they found that the conchae were completely reversed, being convex rather than concave, producing an obvious deformity in otherwise normal ears. The present series of eight patients with similar anomalies suggests that this condition may be underdiagnosed or neglected because of lack of other otological abnormalities. However, some patients may be affected psychologically due to the cosmetic disfigurement produced by this anomaly. The surgical correction of this anomaly, in the form of a modified conchoplasty technique, offers a simple and effective means of restoring the patient's self-confidence and well being.

\section{CASE PRESENTATIONS}

At the authors' institution, eight patients (Table 1) with similar anomalies of the concha, in the form of reverse conchal bowl, were encountered over a three-year period between

Correspondence: Dr Subhash Chandra Shetty, Department of Otolaryngology and Head and Neck Surgery, St John's Medical College Hospital, Bangalore, 560 034, India. Telephone 91-80-5530724 ext 374, fax 91-80-5530735, e-mail stjohns@blr.vsnl.net.in 
TABLE 1

Characteristics of eight patients with reverse conchal bowl

\begin{tabular}{lcccccc}
\hline Patient & Age (years) & Sex & Involvement & Otoscopy and hearing test & Associated findings & Corrective surgery \\
\hline 1 & 28 & $\mathrm{M}$ & Unilateral & Normal & - & No \\
2 & 30 & $\mathrm{~F}$ & Unilateral & Normal & - & No \\
3 & 32 & $\mathrm{~F}$ & Unilateral & Normal & Saddle nose & No \\
4 & 22 & $\mathrm{~F}$ & Unilateral & Normal & - & No \\
5 & 52 & $\mathrm{M}$ & Unilateral & Normal & - & No \\
6 & 40 & $\mathrm{~F}$ & Unilateral & Normal & - & Yes \\
7 & 8 & $\mathrm{M}$ & Bilateral & Normal & No \\
8 & 16 & $\mathrm{~F}$ & Bilateral & Normal & - & \\
\hline
\end{tabular}

F Female; M Male
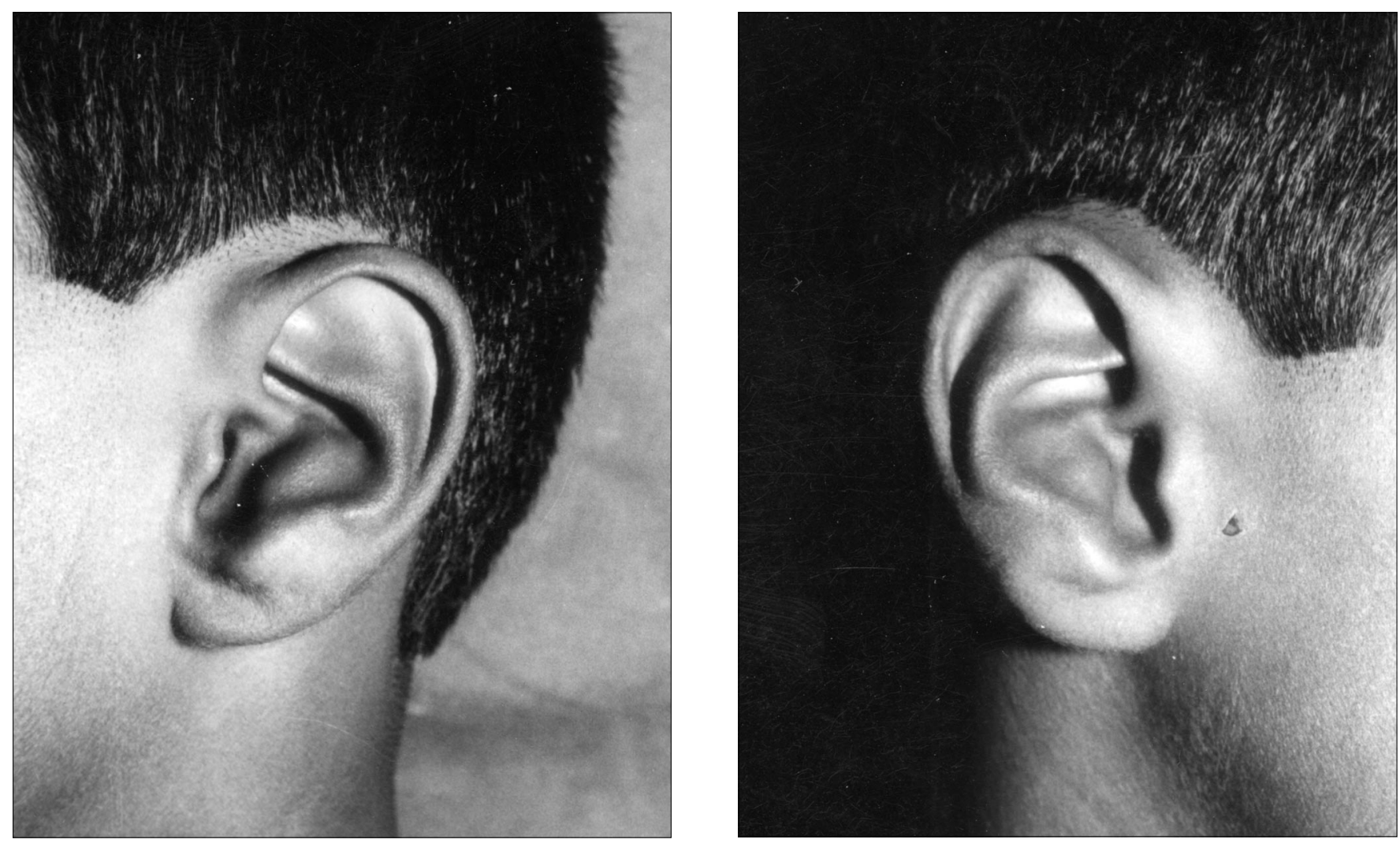

Figure 1) An eight-year-old boy with bilateral convex conchal deformity of the left (Left) and right (Right) ears

1996 and 1998. Ages ranged from eight to 52 years, and there were five female patients. This condition was bilateral in two patients and unilateral in six patients. The two patients who consented to undergo operation were concerned about their appearance. The child, whose bilateral deformity is shown in Figure 1, knew of no other member of his family with a similar ear; he had one female sibling, with normal ears. All patients were healthy and the anomaly was an accidental finding, except in the child mentioned above and an adult who had congenital saddle nose deformity along with unilateral reverse conchal bowl (Figures 2,3). All patients were evaluated by routine otolaryngological and hearing tests with pure tone and impedance audiometry, and were found to be normal.
On examination, the conchae were found to be reversed, assuming the shape of a convex bowl rather than being concave, resulting in an obvious deformity. Detailed physical examination revealed no other congenital abnormality.

A modified conchoplasty technique was used for the two patients who were willing to undergo cosmetic surgery. Bilateral correction was performed on one patient and unilateral correction on the other patient.

\section{TECHNIQUE OF MODIFIED CONCHOPLASTY}

Surgical correction was done under general anesthesia. The desired amount of conchal cartilage to be excised and reversed was first marked out anteriorly on the concha. Lidocaine hydrochloride-epinephrine (Xylocaine parenteral 

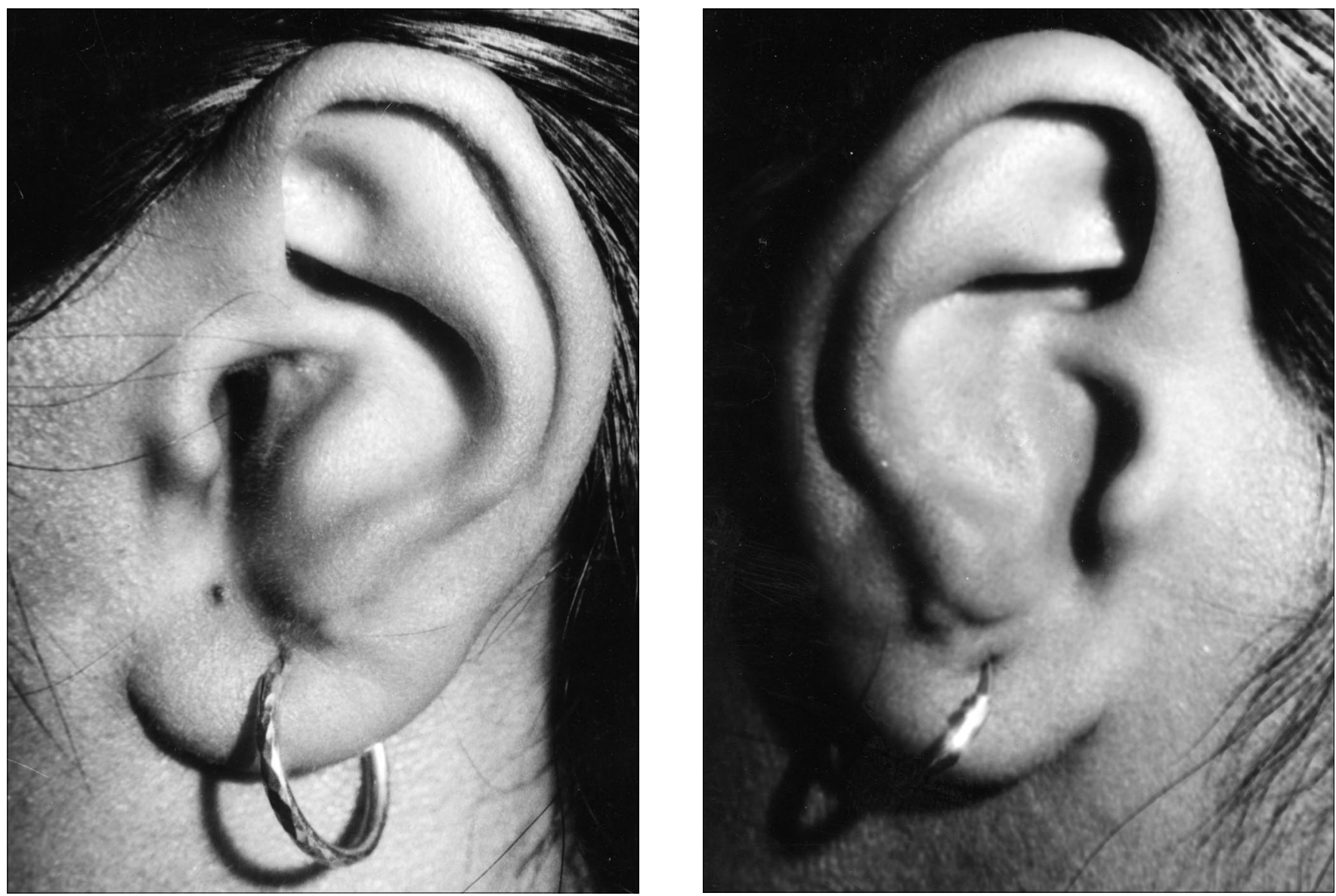

Figure 2) Lateral view of the left (Left) and right (Right) ears showing bilateral convex concha in the second patient

solutions; AstraZeneca, United States) 2\% was infiltrated over the posterior surface of the pinna to create a hydrotomy that aids in dissection. The pinna was displaced forward, and a posterior oblique incision was made without incising an eclipse of skin over the concha.

The posterior surface of the cartilage of the pinna was exposed. A skin hook was used to draw the posterior edge of the incision back, and the mastoid region was freed completely with division of the posterior auricular muscle. Therefore, the whole region where the concha was to be fixed back was exposed. Small hypodermic needles dipped in methylene blue were introduced from the anterior to posterior surface at strategic points along the line that was marked out early in the surgery. The cartilage was incised on the posterior surface along the line connecting the strategic points (Figure 4). The cartilage and anterior perichondrial layer were separated from the skin. The bowl of cartilage was removed and inserted back in reverse fashion and anchored to the rest of the pinnal cartilage using 5-0 nonabsorbable monofilament sutures. The concha was fixed to the mastoid using two 3-0 absorbable sutures, one superior and one inferior. Hemostasis was checked before closing the posterior incision with interrupted 5-0 nonabsorbable sutures. In one case, the same procedure was repeated on the other ear. The ears were then molded with two sheets of antibiotic impregnated petroleum jelly gauze, one on the concha and another on the posterior skin crease, and a firm head bandage was applied and kept on for seven days. Sutures were removed seven days after surgery, and no postoperative complications were encountered. Correction remained satisfactory at six months (Figure 5).

\section{DISCUSSION}

Auricular deformities and aplasias may occur in all degrees, from simple outstanding ears, caused by the absence of the antihelix, to total aplasia (anotia). Malformations of the concha are not very frequent, except for hypertrophy of the concha, which is a deep concha causing prominent ears (2). Rare abnormalities include congenital cleft of the concha and vertical cartilaginous ridge in the concha (crus cymbae) (3). Crus cymbae is found in $5 \%$ to $6 \%$ of ears. It is an irregular dominant character with highly variable expression. At the back of the ear, a projecting cartilaginous lump is sometimes present. It is more frequent in men than women, but its manner of inheritance is unknown (4). Reverse conchal bowl without any other otological abnormalities may be less common than a simple cleft of the concha, which is rare (5).

Congenital deformities of the concha may result in conchal blockade. A collapsed, anteriorly displaced conchal fold, and cartilage abutting the posteromedial surface of the 


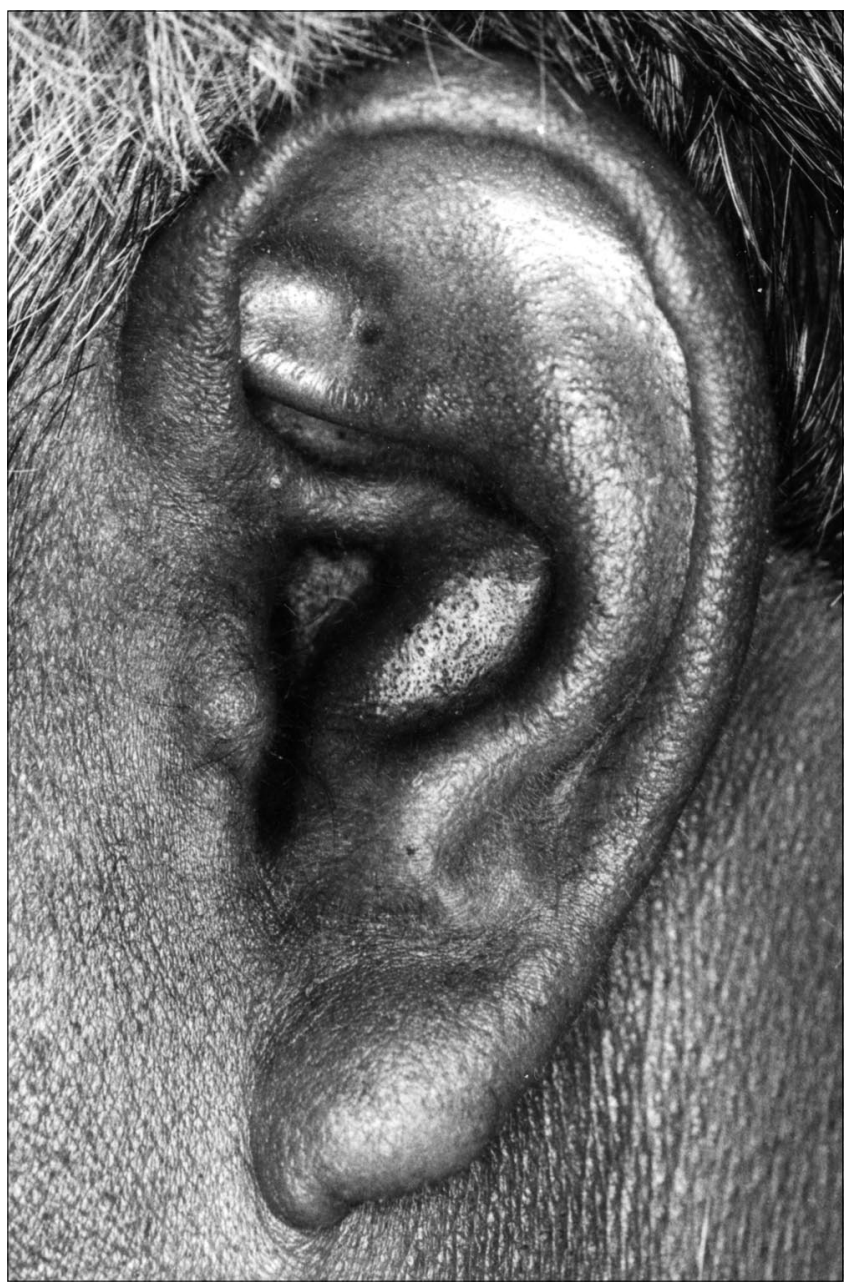

Figure 3) A 52-year-old man with unilateral conchal deformity

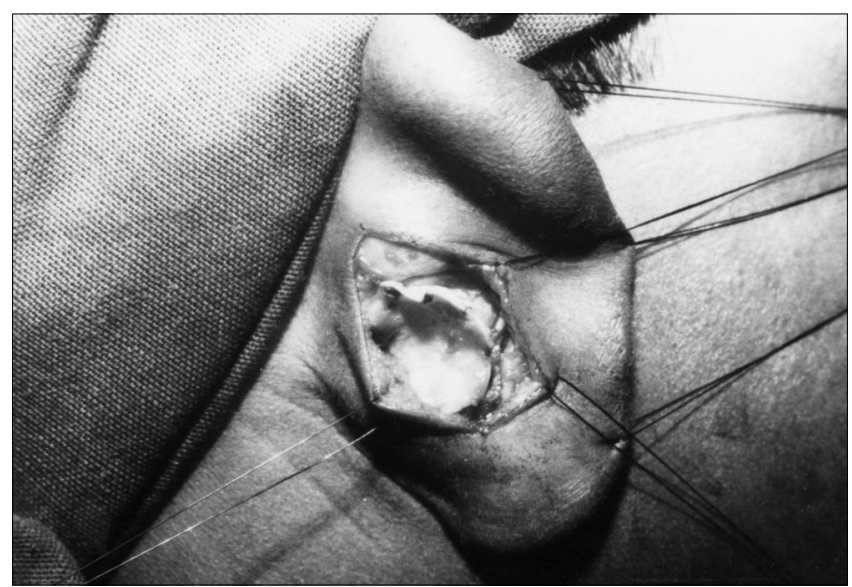

Figure 4) Operative view from behind showing the excision of conchal cartilage along the strategic points, before fixing it in reverse fashion. Note the convexity of the otherwise concave conchal cartilage

tragus, may cause obstruction of the external auditory meatus and intermittent conductive hearing loss (Reger effect) $(6,7)$. The condition is usually bilateral, and some patients learn that they hear better if the auricle is pulled backwards and upwards, pulling the conchal fold away from the tragal contact
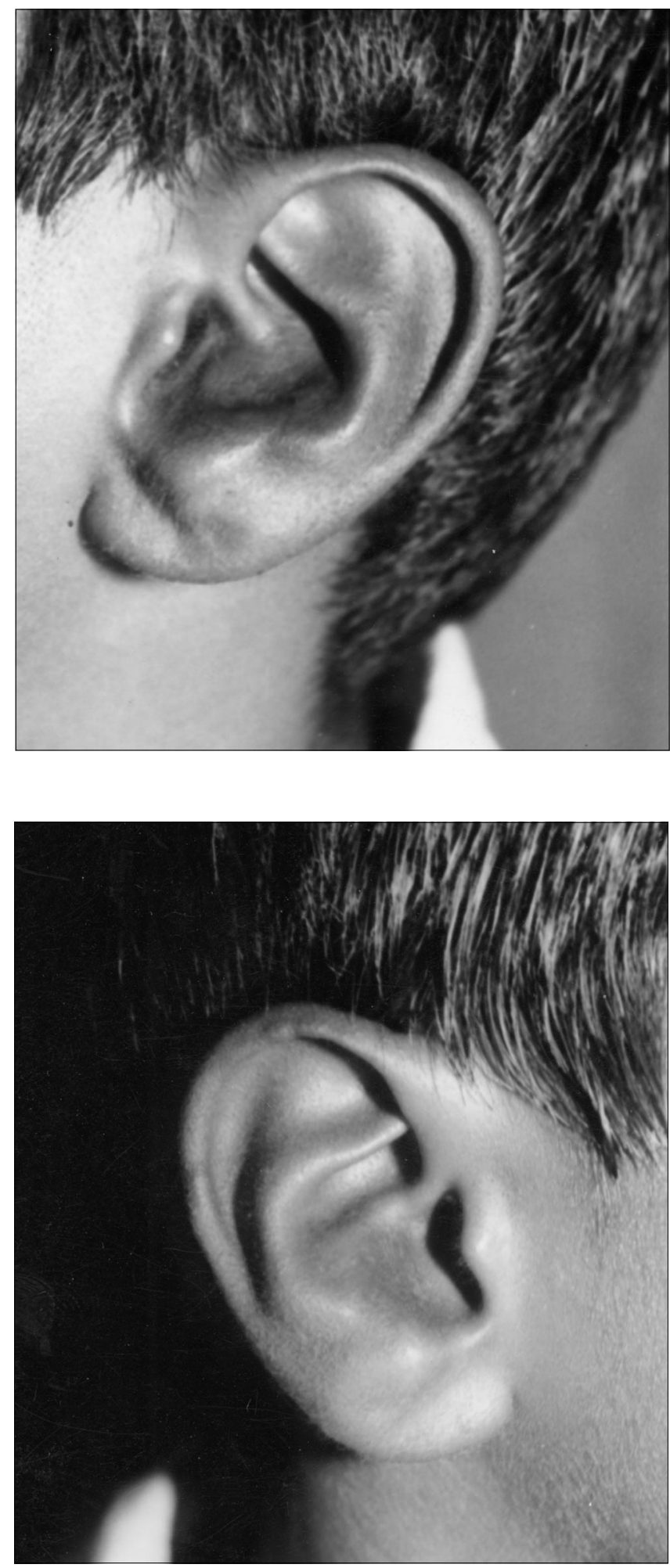

Figure 5) Correction after six months in both left (Top) and right (Bottom) ears of the patient shown in Figure 1

area. The conchal blockade should have been present in all cases, but no patients complained of intermittent hearing loss or frequent cerumen impaction.

Knowledge of embryological development of the external ear has been derived mainly from classic work done by His 

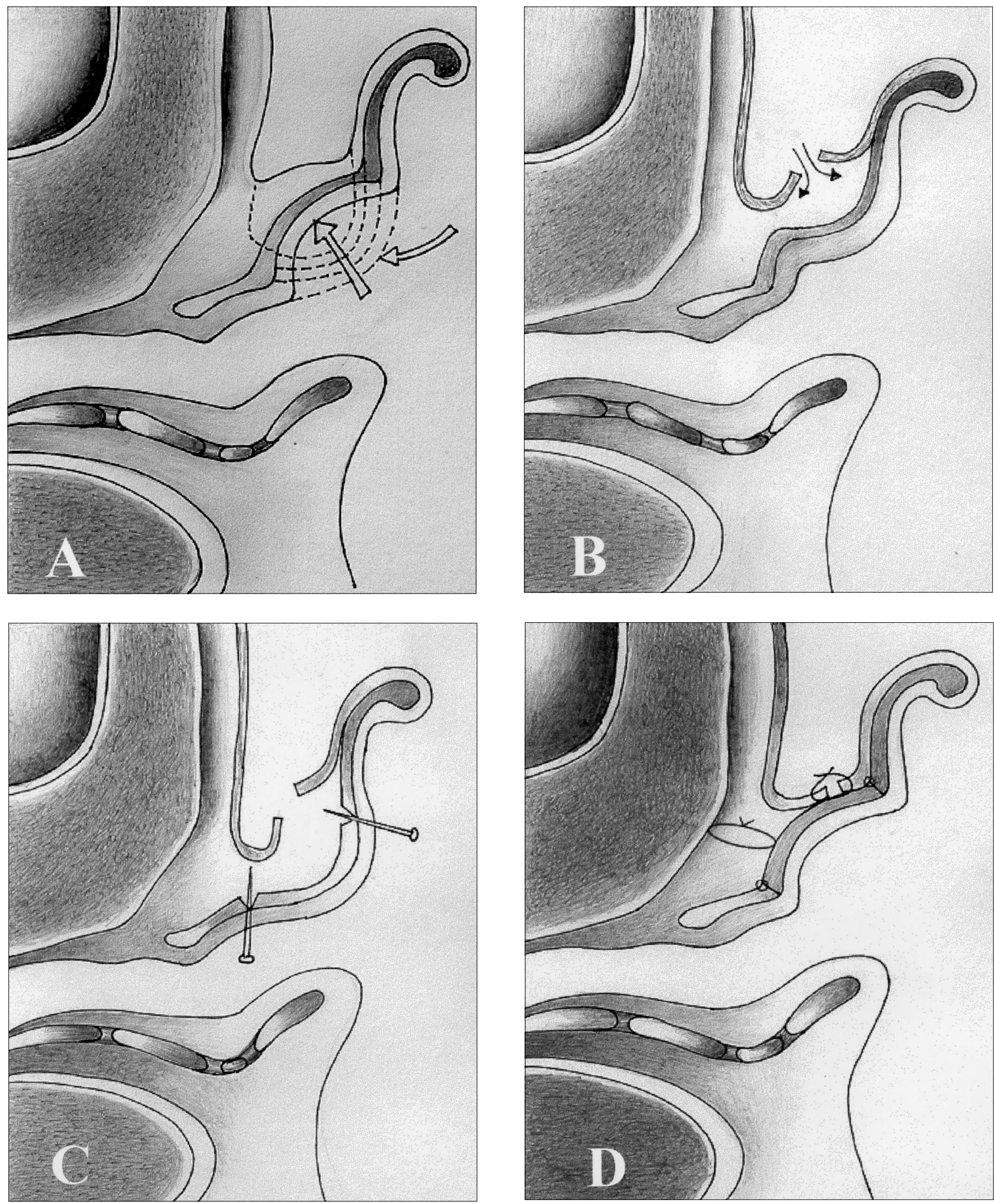

Figure 6) Diagram showing schematic horizontal sections through the auricle. A Normal curvature of the concha (open arrow) and reverse conchal bowl is shown with dotted lines (curved arrow), B posterior approach. C Marking out the concha to be resected and replaced, by hypodermic needles anteriorly. D Placement of resected conchal cartilage in reverse fashion, conchomastoid sutures and closure. Reprinted with permission from reference 15 
TABLE 2

Controversies on the development of the concha

\begin{tabular}{ll}
\hline Author (reference) & \multicolumn{1}{c}{$\begin{array}{c}\text { Assumptions regarding conchal } \\
\text { development }\end{array}$} \\
\hline His and Wilson (8) & $\begin{array}{c}\text { After the fourth month, the concha makes } \\
\text { its appearance behind the tragus } \\
\text { between crushelix and antitragus } \\
\text { Concha is derived from hyoid arch } \\
\text { Ruge (16) }\end{array}$ \\
Hammar (17) & $\begin{array}{c}\text { Concha is derivative of first branchial cleft } \\
\text { The auricle, except the tragus, appears to } \\
\text { be formed from hyoid elevation }\end{array}$ \\
\hline
\end{tabular}

(8) in 1885, and Streeter (9) in 1922. The auricle develops from six mesenchymal proliferations (hillocks) located at the dorsal ends of the first and second pharyngeal arches and surrounding the first pharyngeal cleft. These swellings, three on each side of the external meatus, later fuse and gradually form the definitive auricle. The fusion of the auricular hillocks is rather complicated; hence, developmental abnormalities of the auricle are not uncommon. The only portions of the external ear eventually derived from the mandibular arch are the tragus and the anterior crus of the helical margin, although hyoid arch derivatives include the helix, antihelix, scapha, antitragus and lobule (10).

The cleft lying between the first and second branchial arches becomes the fossa angularis, from which the external auditory meatus eventually develops. The last portion of the external ear to be developed is the concha. By week 20 of development, the ear is nearly anatomically complete. The development of the concha is controversial (Table 2).

Many reconstructive procedures done on the external ear have been described, especially operations to correct prominent ears, first by Edward Ely (11) in 1881. Ely (11) excised a full thickness ellipse of skin and conchal cartilage. In 1890, Keen (12) presented a similar procedure but preferred to leave the anterior skin intact to avoid noticeable scarring in the concha. Only one case report is available on reverse conchal bowl dealing with both the controversial embryogenesis of the external ear and a technique of correction by excision of a crescent of conchal cartilage, adopting the posterior approach (1). We adopted this approach to conchal cartilage resection and replacement, and inverted the concha back in reverse fashion to attain a smooth, concave conchal bowl without leaving a scar anteriorly (Figure 6). Survival of the conchal cartilage that was replaced as a free graft was well documented by Davis (13), who used a triangular conchal cartilage flap to restore the normal height of severe cup deformity (group II B) of the auricle $(13,14)$.

The modified conchoplasty technique differs from that described by Yii and Walker (1) in two ways: first, a posterior incision is made without excising skin, and second, the conchal cartilage is replaced rather than discarded. We feel that the postoperative results are sufficient to warrant this technique over the previously described technique in which the conchal cartilage is discarded. Another advantage of this technique is that the edges of the replaced conchal cartilage were not visible in any patient after surgery, who subsequently obtained a smooth conchal bowl.

\section{REFERENCES}

1. Yii N, Walker CC. Unusual conchal deformity in otherwise normal ears. Plast Reconstr Surg 1996;98:726-9.

2. Evans PHR. Prominent ears and their surgical correction. J Laryngol Otol 1981;95:881-92.

3. Altmann F. Malformations of the auricle and the external auditory meatus. Arch Otol 1951;54:115-30.

4. Quelprud T. Variability and genetics of human external ear. Proceedings at International Congress on Genetics. 1941;7:243-80.

5. Jia-YI Z, Fen H. Congenital auricular deformity consisting of cleft concha and transposition of the earlobe and antitragus. Plast Reconstr Surg 1996;97:428-30.

6. Smith R, Dickinson JT, Teachey WS. Medial conchal excision in otoplasty. Laryngoscope 1975;85:738-50.

7. Storper IS, Canalis RR, Lambert PR. Disease of the auricle and preauricular region. In: Canalis RF, Lambert PR, eds. The Ear: Comprehensive Otology. Philadelphia: Lippincott Williams and Wilkins, 2000:325-39.

8. His W. Die Formentwicklung des ausseren Ohres. In anatomie menschlischer embryonen, 1885, part III, 211.

9. Streeter GL. Development of the auricle in the human embryo. Contrib Embryol 1922;69:111-38.

10. Wood-Jones F, Wen IC. The development of the external ear. J Anat 1934;68:525-30.

11. Ely ET. An operation for prominence of the auricles. Arch Otol 1881;10:97.

12. Keen WW. New method of operating for relief of deformity of prominent ears. Ann Surg 1890;11:49-51.

13. Davis JE. The repair of severe cup ear deformities. In: Tanzer RC, Edgerton ME, eds. Symposium on Reconstruction of the Auricle. St Louis: CV Mosby Co, 1974:134-9.

14. Cardoso AD, Sperly AE. The use of composite grafts to correct the cup ear and to repair small losses of the auricle. Transactions of Fourth International Congress on Plastic and Reconstructive Surgery. Amsterdam: Excerpta Medica Foundation, 1967:667-71.

15. Portmann M, Portmann D. Otologic Surgery: Manual of Otosurgical Techniques. New York: Delmar Publishers, 1998:253.

16. Ruge G. Das Knorpelskelet des ausseren Ohres der Monotremenein Derivat des Hyoid bogeus. Morph Jahrb 1898;25:202.

17. Hammar JA. Studien uber dae Entvicklung des Vorderdarms und einiger angrenz enden organe: I. Abtheilung: Allgemeine Morphologie der Schlundspalten beim Menschen Entwicklung des Mittelohrraumes und des ausseren Gehorganges. Arch Mikr Anat 1902;59:471. 